\title{
O RECONHECIMENTO DO DIFERENTE: LIDANDO COM 0 MULTICULTURALISMO E A INCLUSÃO A PARTIR DA TEORIA DE HABERMAS
}

RESUMO: A recepção de estrangeiros e minorias dentro dos Estados, a partir dos movimentos e fluxos migratórios, faz surgir a necessidade de políticas inclusivas do diferente e de reconhecimento de direitos fundamentais em nível mundial e nas sociedades que os recebem. Nesse contexto, temas como democracia, multiculturalismo, universalização dos direitos humanos, legitimação das políticas inclusivas passam a ser objeto desse estudo, que tem por objetivo analisar as reflexões de Habermas sobre esses temas e percorrer o caminho por ele traçado para justificar a legitimação da inclusão do outro a partir da teoria do discurso, da participação efetiva dos envolvidos nos debates e na construção de leis formais democráticas que assegurem os direitos humanos. 0 método hermenêutico permite realizar a análise crítica da obra "A Inclusão do Outro", refletindo sobre as construções teóricas do filósofo alemão para justificar a inclusão do diferente nas sociedades multiculturais e seculares. Em conclusão, reafirma-se a construção teórica de Habermas como um horizonte filosófico a ser buscado pela sociedade mundial, sem, contudo, deixar de reconhecer a dificuldade de sua implementação.

PALAVRAS-CHAVE: Inclusão; Direitos humanos; Multiculturalismo; Reconhecimento; Teoria do discurso.

\section{ACKNOWLEDGING THE DIFFERENT OTHER: MULTICULTURALISM AND INCLUSION IN HABERMAS}

\begin{abstract}
Welcoming foreigners and minority populations by the State from migratory movements and flows requires inclusive policies of the different other and the acknowledgement of fundamental rights worldwide and in the communities that receive them. The themes of democracy, multiculturalism, human rights for all, legitimating inclusion policies constitute current analysis. In fact, it investigates Habermas's thoughts on the themes and discusses the reasons to justify the inclusion of the other from the point of view of Discourse Theory, the effective participation of those involved in the debates and in the construction of formal democratic laws that safeguard human rights. The hermeneutic method critiques the Inclusion of the Other and reflects on the theoretical constructions of the German philosopher to justify the inclusion of the different Other in multicultural and secular societies. Habermas's theory lies within a philosophical horizon that should be sought after by world populations, without underestimating the difficulties involved.
\end{abstract}

KEYWORDS: Inclusion; Human rights; Multiculturalism; Acknowledgement; Discourse theory.

\section{A INCLUSÃO DO OUTRO}

Uma das grandes questões com as quais os Estados contemporâneos se deparam é a inclusão de minorias e agrupamentos humanos que diferem do ethos da sociedade que os abarcam e recebem, tendo em vista as implicações da fluidez das fronteiras, dos conflitos intratáveis que expulsam contingentes populacionais para outros países, perseguições políticas e até a busca por novas condições de vida. Dessa realidade de trânsitos humanos, em um contexto de fronteiras porosas, emerge, de forma mais contundente, um cenário de fragmentação das sociedades, que veem sua identidade transformada pela presença de outras identidades diferentes, tornando indispensável a adoção de políticas de reconhecimento para permitir um multiculturalismo saudável e inclusivo. 
É com 0 intento de buscar um fundamento universal para a inclusão do diferente nas sociedades cosmopolitas, a partir de uma abordagem hermenêutica, de revisão bibliográfica, que o presente artigo se desenvolverá. 0 estudo terá como foco a teoria do discurso de Jürgen Habermas, que enfatiza as relações de reconhecimento e reciprocidade a partir de uma fundamentação filosófica da democracia e dos direitos humanos em perspectiva cosmopolita.

Em "A Inclusão do Outro", Habermas reflete sobre a teoria do discurso e sua importância para a fundamentação da justiça e da democracia, a relação entre direito e moral, a legitimação dos direitos humanos e suas origens, a inclusão do outro no cenário multicultural, a tese da cooriginaridade entre soberania popular e direitos humanos, a pressuposição mútua entre autonomia pública e privada, o projeto kantiano de paz perpétua. Todos esses tópicos são perpassados pelo fio condutor de um novo cosmopolitismo, no sentido da construção universal e procedimental da justiça que dê conta da inclusão do diferente. A partir da análise da obra em comento, procura-se saber como fundamentar a inclusão do diferente nas sociedades plurais, por meio da garantia de direitos humanos na política de reconhecimento das identidades culturais minoritárias.

A constatação de que os Estados nacionais devem repensar a ideia de soberania, para que possam se inserir em uma sociedade mundial, faz emergir a necessidade da análise dos fundamentos legitimadores das soberanias parciais e dos vínculos de coesão e viabilidade de convivência entre os diferentes, dentro das comunidades às quais pertencem.

No percurso de investigação dos elementos legitimadores do conteúdo universalista dos princípios viabilizadores da coexistência multicultural, $\mathrm{Ha}$ bermas começa defendendo "o conteúdo racional de uma moral baseada no mesmo respeito por todos e na responsabilidade solidária geral de cada um pelo outro" (HABERMAS, 2002, p. 7). Sua preocupação é encontrar uma forma de legitimação social e política, que valorize a estrutura relacional da alteridade e da diferença e que possa ser validada por um universalismo bem entendido. Aos Estados democráticos contemporâneos é reconhecida a incumbência de lidar com uma diversidade de identidades culturais que reivindicam suas necessidades enquanto grupo. Tais Estados devem pensar e garantir modelos de proteção não só a esses grupos não congêneres, mas também aos indivíduos que deles fazem parte. São realidades incontestáveis não somente de países europeus e do atlântico-norte, mas também de muitas democracias subdesenvolvidas que recebem contingentes de refugiados.

Estados democráticos são criações artificiais, que englobam em seu interior diferentes grupos que se identificam pela etnia, religião, parentesco, mesma origem ancestral etc ${ }^{2}$. Tais grupos mantêm a coesão entre seus indivíduos por noções de lealdade pelo liame de parentesco ou de compartilhamento de crenças. E, acaba sendo senso comum, pela própria historiografia dos Estados que secularmente recebem imigrantes, que o diferente, aquele que não compartiIha daquele ethos original da cultura do Estado que os recebe, raramente é reconhecido e incluído no 'novo lar'.

Nesses contextos, as democracias devem zelar pela coesão entre grupos diversos, para, assim, permitir igual consideração mútua e o reconhecimento e garantia de iguais direitos fundamentais para todos. Esse posicionamento, entretanto, não é de todo compartilhado. Habermas, ao contrário, se filia à vertente da inclusão, do reconhecimento de todos, com base em um tratamento solidário.

Quando centenas de milhares de pessoas, muitas delas com diferentes religiões e visões de mundo, vêm para um país, o próximo passo é a integração. Existe uma chave filosófica para uma integração bem-sucedida?

Existe uma base comum sobre a qual a integração deve acontecer, e esta é a Constituição. Trata-se de princípios que não estão escri-

\footnotetext{
Para Habermas, a 'consciência do nós', fundada em um parentesco imaginário de sangue ou identidade cultural, "de pessoas que compartilham a crença numa origem comum e se identificam mutuamente como 'membros' de uma mesma comunidade, diferenciandose assim dos que os rodeiam, deveria constituir o cerne comum das comunidades étnicas pela sua complexidade e tamanho" (HABERMAS, 2002, p.148). Para ele, esse é um conceito etnológico de nação que concorre com o conceito historicamente empregado, eis que apaga as referências à ordem do Estado democrático de Direito.
} 
tos na pedra, mas que devem ser discutidos num amplo processo democrático. Eu acho que esse debate vai acontecer mais uma vez entre nós. Devemos esperar de cada pessoa que acolhemos que ela respeite nossas leis $\mathrm{e}$ aprenda a nossa língua. Ao menos na segunda geração, também devemos esperar que aconteça uma interiorização normativa de nossa cultura política ${ }^{3}$.

As sociedades modernas, funcionalmente coesas pelo direito, pelo 'sistema' e 'mundo da vida' compartilhados intersubjetivamente (HABERMAS, 2002; 2003a) "continuam a se delimitar umas as outras como nações" (HABERMAS, 2002, p. 149), o que não gera, automaticamente, autoentendimento nacional. Nesse ponto, Habermas propõe a questão empírica de saber como, quando e em que medida "as populações modernas se entendem a si mesmas como uma nação de membros de um povo ou de concidadãos" e, ainda, como uma cultura majoritária, no exercício do poder político, inflige às minorias a sua forma de vida, negando aos cidadãos de origem cultural diversa uma efetiva igualdade de direitos (HABERMAS, 2002, p. 149; 170). Com essa preocupação, faz um percurso pela genealogia da moral, com 0 objetivo de reforçar a ideia de que uma moral racional, que prescinde de digressões conteudistas e que advém de uma ética discursiva contribui para a fundamentação de uma integração solidária entre estranhos, no reconhecimento mútuo a partir da alteridade e na atribuição de direitos iguais para todos, nacionais e estrangeiros, com base, também na fidelidade a princípios universalistas.

A inclusão do diferente é desejável e necessária, é condição de integração política e significa respeito às diferenças por parte de uma cultura política comum e a viabilização jurídica do exercício de direitos fundamentais por todos, o que contribui para a não eclosão de conflitos decorrentes da inserção ampliada em contraposição ao fechamento e repúdio ao "outro" pelos nacionais.

\footnotetext{
3 Entrevista concedida por Jürgen Habermas à rede de televisão Deutsche Welle, em 01 de outubro de 2015, ao receber o prêmio John W. Kluge (Cf. RUTA, 2014)
}

\section{EQUIPRIMORDIALIDADE ENTRE AUTONOMIA IN- DIVIDUAL E PÚBLICA}

Habermas trata da equiprimordialidade entre autonomia individual e autonomia pública, ou entre direitos individuais e soberania popular. Essa tese é construída como proposta de uma terceira via ao debate liberalismo versus comunitarismo, ou seja, não vê preponderância de uma autonomia sobre outra, mas a igualdade, ou a equiprimordialidade, o que faz surgir a tese, também, da cooriginariedade entre direitos humanos e Estado constitucional democrático.

Para Habermas, a equiprimordialidade sustenta a cooriginalidade entre democracia e direitos humanos, ou vice-versa, não havendo Estado democrático sem direitos humanos, nem direitos humanos fora de uma ordem democrática. Essa tese leva à gênese lógica que Habermas busca para os direitos humanos, assentando uma teoria reconstrutiva do direito, a partir do surgimento da legitimidade pela legalidade. Para tanto, toma como ponto de partida "os direitos que os cidadãos têm que atribuir uns aos outros, caso queiram regular legitimamente sua convivência com meios do direito positivo" (HABERMAS, 2003a, p. 113).

A valorização do direito racional positivo, pois, como constituidor dos Estados modernos e do poder político, apresenta uma dupla resposta à questão da legitimação pós-metafísica: o princípio da soberania popular, de um lado; e, de outro, os direitos humanos positivados, havendo entre eles um nexo problemático, uma concorrência "não apaziguada entre direitos humanos e soberania do povo, no interior da tradição do direito racional" (HABERMAS, 2003a, p. 115) que só pode ser apaziguada, de modo satisfatório, por meio da mencionada equiprimordialidade. A legitimidade, então, surge da legalidade na medida em que esta se consubstancia num procedimento de criação do direito positivo por meio do discurso racional, que garante tanto a autonomia privada quanto a pública. Por outro ângulo, um direito que assegure tanto os direitos subjetivos de ação quanto os direitos políticos de participação no processo de formação da vontade racional. Essa gênese lógica é garantida pela ênfase 
dada à cooriginaridade entre autonomia privada e pública, entre direitos humanos e soberania popular. 0 sistema de 'cooriginaridades' leva à reflexividade na criação do direito, ou circularidade.

Ademais, Habermas constrói um conceito de justiça intrinsecamente ligado ao conceito de direitos humanos e à concepção ético-procedimental do direito. 0 direito, para ele, serve como médium para a emancipação do homem e para a coesão social, por conter uma coercilibidade forte, ao passo que a moral possui uma força fraca de coesão (HABERMAS, 2003b, v.1). Ele foca no espaço público, que é onde se desenvolve uma forma de comunicação guiada pela razão e que mantém a coesão da sociedade, reconhecendo que existem fronteiras entre o direito e a moral e que é incompleta a racionalidade procedimental do discurso moral, não regulado juridicamente, sendo, portanto, incompleta. No campo das obrigações morais, não há um terceiro encarregado de decidir as questões entre as partes e desse fato decorre que a moral não possui o mesmo grau de coercibilidade e de estabilização que 0 direito, conforme reflete Marcelo Neves (1996).

Sem resvalar para construções metafísicas ou ancoradas somente na moral, Habermas se utiliza da teoria do discurso para construir seu edifício de legitimação, eis que ela reveste o processo democrático sem apelar apenas para os direitos liberais ou primazia dos direitos humanos frente à soberania popular e sem supervalorizar o modelo republicano, ancorado na ideia rousseaniana de contrato social e restrição de direitos individuais em prol da construção de uma comunidade autorregulada. A partir dessa formação democrática da vontade e da opinião, são construídos, legitimamente, o Estado, o ordenamento jurídico e os direitos humanos. Abstratamente, a teoria do discurso reflete a situação na qual os participantes, independentemente de diferença culturais, políticas, étnicas ou religiosas, dialogam para chegar a um entendimento acerca das normas a serem positivadas para regular a coexistência, conforme leciona Jeffrey Flynn (2011).

Mas o consenso sozinho, a partir do exercício do discurso, não garante a legitimação dos direitos humanos. 0 consenso precisa estar inserido em um contexto democrático, possibilitado pela práxis constituinte, única a vincular o exercício da soberania popular ao sistema de criação de direitos (HABERMAS, 2013, p. 5). Assim, a autolegislação democrática passa a ser viável apenas a partir da instituição de um regime democrático que garanta a participação efetiva dos concernidos nos processos de produção legislativa. Se o discurso racional é necessário à conformação da democracia, a intersubjetividade passa a ser elemento inseparável, uma vez que ínsita ao processo de entendimento. E se 0 processo de alcance do entendimento pelo agir comunicativo é inerente à formação do direito, é forçoso admitir que a tese habermasiana de fundamentação dos direitos humanos pela produção democrática da autolegislação e pela moral foge da tradicional dicotomia liberal-republicana. Ademais, a finalidade da tese da dualidade dos direitos humanos e da equiprimordialidade entre soberania popular e direitos fundamentais rechaça a ideia individualista e atomística da valorização da autonomia individual. Para Habermas, essa autonomia individual relaciona-se não a uma individualidade egoística, mas à autodeterminação e às liberdades de comunicação e de participação no processo democrático, juridicamente institucionalizado.

Com a derrocada das "cosmovisões metafísicas ou religiosas, imunes à crítica, as orientações práticas só podem ser obtidas, em última instância, através de argumentações, isto é, através de formas de reflexão do próprio agir comunicativo" (HABERMAS, 2003a, p. 132) que pressupõem e almejam 0 mútuo entendimento por meio do exercício dos argumentos, em arenas nas quais todos os concernidos tenham voz. Somente com esses pressupostos teóricos e práticos, as democracias poderão incluir 0 diferente e reformular suas ordens jurídicas de modo a reconhecer os direitos das minorias e incluí-las efetivamente sob a proteção do Estado.

\section{POR UMA TEORIA DA JUSTIÇA CONDIZENTE COM O MULTICULTURALISMO: 0 DEBATE COM RAWLS}

Habermas busca na teoria de Rawls uma fundamentação pós-metafísica para a inclusão do 
outro, não congênere, nas sociedades cosmopolitas. Antes, nessa procura por fundamentos de caráter universalista, Habermas aposta em uma concepção ético-procedimental ${ }^{4}$, construída com base na teoria do agir comunicativo, que tem por pressuposto a ética do discurso, tendo este um lugar na 'esfera pública', entendida como espaço democrático, discursivamente autônomo em relação ao 'sistema', sumamente entendido como a esfera do poder e do dinheiro. No tocante à importância dos fundamentos filosóficos e jurídicos para a verdadeira inclusão do outro, $\mathrm{Ha}-$ bermas recorre a Rawls e com ele debate acerca de questões relacionadas à teoria da justiça. Se o filósofo alemão parte de uma teoria discursiva e dialógica para fundamentação da justiça, o filósofo norte-americano reabilita noções morais a partir da ideia kantiana do bom sobre 0 justo. 0 que é bom para todas as pessoas deve ser universalizável.

No entender de Habermas, Rawls reabilitou esse princípio sem recorrer aos pressupostos fundamentais da metafísica kantiana (HABERMAS, 2002, p. 61), com a finalidade de reforçar a justa convivência entre os cidadãos de uma comunidade política. Ainda, reconhece que Rawls assumiu uma posição vanguardista contra o utilitarismo e o ceticismo ao propor uma leitura intersubjetivista do conceito kantiano de autonomia, segundo a qual "agimos de forma autônoma quando obedecemos estritamente às leis que todos os envolvidos poderiam aceitar com boas razões, com base em um uso público de sua razão" (HABERMAS, 2002, p. 61). Por meio desse conceito moral de autonomia, Rawls explica a autonomia pública dos cidadãos em um Estado democrático de Direito. Enfatiza uma teoria política, procurando manter intocadas todas as doutrinas religiosas, metafísicas e morais para se basear em uma filosofia política autossustentável.

Habermas admira esse projeto, compartilhando algumas de suas intenções que considera corretas. Mas diverge em alguns pontos, reconhecendo, ele

\footnotetext{
4 Para Habermas, a modernidade resulta da evolução da consciência moral no sentido da "superação das estruturas pré-convencionais e 0 advento de uma moral pós-convencional", o que significa que há uma clara diferença entre sistema e mundo da vida, diferenciação essa preconizada pelo filósofo alemão como sendo decorrente do processo de evolução social. 0 sistema, para ele, é um espaço de intermediação do 'agir racional com respeito a fins', um agir instrumental e estratégico, enquanto que o mundo da vida constitui horizonte do agir comunicativo, consubstanciado na ação orientada pela busca pelo entendimento intersubjetivo e consenso.
}

próprio, que esses dissensos acabam ficando "dentro dos estreitos limites de uma briga de família" (HABERMAS, 2002, p. 62).

Lembrando que Rawls mantém seus pés fincados no liberalismo, na valorização da autonomia, da liberdade e também da igualdade, em busca de uma neutralidade por ser racional. Sua teoria de justiça é cunhada de 'justiça como equidade', justamente por almejar abarcar a sociedade plural contemporânea a partir da ótica de um Estado democrático constitucional $^{5}$. Ele institui princípios que permitam garantir a cooperação justa e imparcial entre os cidadãos de uma sociedade moderna e constrói conceitos para viabilizar a fundamentação de sua concepção contratualista de uma justiça como equidade. Primeiramente, ele estabelece a ideia de 'posição original', ou condição primitiva, que é uma ideia fictícia a partir da qual os indivíduos racionais e livres se imaginam em uma mesma posição de igualdade e, nessa situação, quais direitos eles se outorgariam: em termos contratuais, quais direitos e deveres eles estabeleceriam para fundamentar o convívio social.

A esse momento hipotético, Rawls denomina 'véu da ignorância', no qual os indivíduos estariam desvinculados de seus projetos de vida, não conhecendo qual 0 estado econômico, cultural 0 político onde estariam inseridos na vida social. Isso porque suas posições morais, filosóficas ou religiosas não poderiam influenciar a deliberação na posição original, eis que comprometeriam o seu resultado final, desvirtuando o conteúdo essencialmente político dos princípios de justiça.

John Rawls deixa claro que a escolha de princípios que abarquem a pluralidade social só é factível considerando-se uma concepção política de justiça $\mathrm{e}$ não uma doutrina moral abrangente. É na busca por princípios também universais que Rawls constrói a figura do "véu da ignorância", que pode ser entendida

\footnotetext{
John Rawls visa a estabelecer uma estrutura necessária para que doutrinas abrangentes profundamente divergentes, ainda que razoáveis, possam conviver nas sociedades plurais e que todas endossem a concepção política do regime constitucional, ou seja, pretende o consenso entre sujeitos racionais dotados de autonomia moral acerca do conteúdo de princípios de justiça necessários para regular a estrutura básica de uma sociedade plural.
} 
como um ponto de contato da filosofia política rawlsiana com a filosofia kantiana ${ }^{6}$. Ele retira das partes, na posição original, o conhecimento sobre circunstâncias pessoais que pudessem corromper 0 acordo social, fazendo com que procurem um consenso baseado em valores universais e na capacidade de serem racionais e de agirem a partir de sua concepção do que é bom, em cada caso.

Embora reconheça pontos de contato entre sua filosofia e a filosofia política rawlsiana, Habermas levanta dúvidas quanto ao fato de ser "a condição primitiva apropriada para explicar e assegurar o ponto de vista do julgamento imparcial de princípios de justiça entendidos de modo deontológico" (HABERMAS, 2002, p. 63). Ainda, critica a teoria rawlsiana nos seguintes pontos: (a) por ter como consequência uma construção de um modelo de Estado de Direito que subordina 0 princípio de legitimação democrática a direitos liberais fundamentais; (b) por entender que a posição original e o véu da ignorância propugnam que os indivíduos, por meio desses artifícios metodológicos ${ }^{7}$, não poderiam observar as coisas a partir de um ponto de vista moral, uma vez que a imparcialidade e neutralidade são essenciais para Rawls.

Nesse ponto, Habermas levanta três questionamentos: (1) as partes podem, na condição original, perceber apenas com base em seu egoísmo racional e interesses prioritários? (2) é lícito que os direitos fundamentais sejam assimilados como bens fundamentais?; (3) 0 véu da ignorância garante a imparcialidade do juízo? (HABERMAS, 2002, p. 65). Com relação ao primeiro questionamento, Habermas afirma que Rawls não consegue sustentar sua tese, uma vez que os cidadãos, pressupostamente, são pessoas morais, que possuem um senso de justiça e uma con-

6 A ideia de imperativo categórico, para Kant, expressa um modelo de conduta em que os indivíduos devem basear-se, devendo orientar-se de modo que a sua ação possa ser elevada a uma máxima de comportamento universal.

7 Pela posição original e pelo véu da insciência, as partes livres e iguais reciprocamente desinteressadas umas pelas outras não sabem que posição irão ocupar na sociedade por elas ordenadas, por isso, por seus próprios interesses, pensariam a respeito do que seria uniformemente bom para todos. Rawls insistiu nessa tese, defendendo que 0 ponto de vista moral deveria ser assim operacionalizado. Essa insistência fez com que Habermas refletisse sobre três consequências dessa postura, tidas por ele como desagradáveis (HABERMAS, 2002, p. 64-65). cepção própria do bem. Como a construção da posição original e do véu da ignorância são objetivamente racionais, os envolvidos seriam desonerados justamente dessas características racionais das pessoas morais (HABERMAS, 2002, p. 65-66).

Ainda na esteira da análise do pano de fundo crítico das teorias que fundamentam diferentes vertentes da política de reconhecimento, Habermas contextualiza e critica a revisão que Rawls fez, em 1993, sobre sua teoria da justiça como equidade. A necessidade dessa revisão surgiu em decorrência da acentuação do processo de globalização, diluição de fronteiras e da emergência de discussões acerca do multiculturalismo e inclusão do outro. Nesse contexto, as concepções liberais de justiça, de viés kantiano, começaram a sofrer severas críticas por parte da corrente denominada comunitarista, que passou a repudiar a neutralidade das políticas de justiça fundamentadas no liberalismo, corrente à qual pertence Rawls, Ronald Dworkin, dentre outros.

Entretanto, J. Rawls ainda adotou a estratégia kantiana, recorrendo a um ponto de vista moral a partir da ideia de posição original. Sua construção da teoria da justiça como equidade recorreu à razão prática, que remete à noção de capacidade elevada de uma pessoa moral. Nesse construtivismo kantiano propugnado por Rawls, segundo Habermas (2002, p. 97-98), a razão perde sua posição central e forte, sendo "deflacionada à condição de uma racionalidade que incorre na dependência em relação a verdades morais fundadas em outras bases" (HABERMAS, 2002, p. 98). A teoria da justiça de Rawls, a partir da obra "Liberalismo Político", de 1993, passa a se fundamentar, então, "não mais em uma razão prática vinculativa geral, mas a partir da convergência de imagens de mundo racionais que se superpõem de forma suficiente em seus constituintes morais" (HABERMAS, 2002, p. 98).

A tentativa de aliviar um pouco o liberalismo acentuado que caracteriza a teoria da justiça como equidade não logrou êxito, na visão de Habermas. Isso porque Rawls continua a insistir em um consenso abrangente e em um caráter 'vago' dessa 
teoria, sendo esse predicado entendido como anseio político (HABERMAS, 2002, p. 91) ou então como uma tentativa de contornar todas as questões controversas da metafísica, a partir da construção de uma barreira imaginária que deixaria a filosofia, por exemplo, onde ela está e como ela é.

Com relação a esses aspectos, entendese que Rawls recorre às categorias que desbordam da esfera política sem, no entanto, tomar posição com relação a questões filosóficas. Para ele, o consenso abrangente sobre justiça política depende de uma teoria neutra e não de categorias metafísicas ou fora da esfera política. Nesse ponto, Habermas reflete que a expressão 'metafísico' ganha sentido próprio em oposição a 'político' e frisa que Rawls argumenta que as sociedades contemporâneas, acentuadamente pluralistas, "dependem de um consenso abrangente sobre questões relacionadas à justiça política, e neutro em relação a visões de mundo em particular" (HABERMAS, 2002, p. 91) e que teorias que apoiem tal consenso devem ser políticas e não metafísicas, atendo-se somente ao campo do político e não do metafísico. Para Rawls, ainda, as teorias têm que se manter neutras e isentas de controvérsias filosóficas.

Entretanto, com razão, Habermas defende que a filosofia, em razão de sua institucionalização, não cultiva necessariamente uma relação interna com o que é da metafísica, tendo por fim uma busca cooperativa pela verdade, razão pela qual intenta uma checagem sobre a relação entre político e o metafísico, que reflete na dependência do "racional em ração ao verdadeiro" (HABERMAS, 2002, p. 92)

Enquanto os cidadãos racionais não tiverem em condições de adotar um ponto de vista moral que se mostre independente das perspectivas das diferentes imagens de mundo assumidas por cada um deles em particular e que a preceda, não podemos esperar deles um consenso abrangente. Na busca por esse consenso, ele tenta demonstrar que Rawls não conseguiu evitar o total esvaziamento das exigências da razão prática e que o conceito de racional ora torna-se atenuado demais para assinalar a validade de uma concepção de justiça subjetivamente reconhecida, ora é definida de forma severa.
0 liberalismo político e 0 comunitarismo apresenta suas respostas ao desafio do multiculturalismo. 0 liberalismo volta-se a um consenso fundamental que assegure liberdades iguais a todos os cidadãos, independentemente de sua origem cultural, tradições, crenças, visão de mundo. Ele abarca todos, em uma pretensão universalista, sem levar em conta, todavia, a necessidade de efetivas políticas materiais inclusivas. Por fim, Habermas conclui que nem 0 comunitarismo nem o liberalismo, cujo modelo finca raízes na teoria da justiça como equidade, de Rawls, oferecem justificações pós-metafísicas suficientes para a adoção de bases morais universais e, por conseguinte, para fundamentar o universalismo dos direitos humanos em um cenário plural.

\section{A PAZ PERPÉTUA EM KANT E O RECONHECIMEN- TO E ETICIDADE REFLEXIVA}

A discussão da teoria da justiça com Rawls deve ser complementada pelo debate da paz perpétua e do direito cosmopolita com Kant. Não obstante reconheça os avanços alcançados por Kant, tece críticas à forma como ele concebeu, 200 aos atrás, a ideia de uma sociedade cosmopolita sem que houvesse um médium coercitivo responsável pela união das ordens jurídicas parciais. Kant previa que essa união seria moral, o que fez com que houvesse uma força fraca de coercibilidade que as mantivessem unidas.

Habermas critica a saída kantiana e propõe que os direitos humanos universais sejam resguardados por um órgão com legitimidade democrática, representativo de todas as unidades jurídicas parciais, e com força executiva, para fazer valer esses direitos em caso de descumprimento. No ensaio sobre a Paz Perpétua, ele também rechaça as críticas feitas por Carl Schmitt ao universalismo. Schmitt afirma que os direitos humanos se relacionam a uma hipocrisia de um pacifismo jurídico que faz guerras tidas por seus adeptos como justas, em nome da paz e de um direito cosmopolita. Schmitt teceu seus argumentos contra os direitos humanos a partir da concepção de que 
'humanidade', por si só, já é um conceito ideológico, utilizado pelos Estados nas políticas de dominação, intervenções e guerras em nome da defesa desta 'humanidade'. Em sua opinião, conforme descreve Habermas, a política de uma organização mundial plural inspirada na ideia de Kant de paz perpétua e "que visa à construção de uma condição cosmopolita obedece à mesma lógica: 0 pan-intervencionismo leva obrigatoriamente a uma pancriminalização e, com isso, à perversão dos objetivos aos quais ela se propõe servir" (2002, p. 212).

Dessa feita, argumentos contrários à política dos direitos humanos, em regra, partem do fato de que essa mesma política causa guerras que assumem qualidade moral. Essa moralização, segundo Habermas, acarreta a rotulação dos opositores como inimigos, justificando atos contrários à própria humanidade que os direitos humanos visam a proteger. Assim, conceitos como direitos humanos, democracia, bem comum são vistos como instrumentos ideológicos de dominação, utilizados para revestir atos de intervenção e expansão de poder com aura de legitimidade.

Para Habermas, esses argumentos utilizados pelos opositores das políticas de direitos humanos, quais sejam: de moralização da política e, portanto, da guerra dela consectária e classificação dos opositores como inimigos - são fundamentados em duas premissas:

(a) a política dos direitos humanos serve à imposição de normas que são parte de uma moral universalista; (b) como juízos morais obedecem ao código de "bem" e "mal", a valoração moral negativa (de um oponente político ou) de um opositor bélico destrói a limitação juridicamente institucionalizada (da confrontação política ou) do combate militar (2002, p.213) ${ }^{8}$.

Ainda, nesse ensaio, o filósofo alemão alude ao sentido moderno dos direitos humanos, afirmando que ele se liga às declarações de direitos do final do século XVIII, cuja construção se deu em alicerces li-

\footnotetext{
8 Para Habermas, enquanto a premissa 'a' é falsa, a 'b', no contexto de uma política de direitos humanos, sugere um pressuposto falso.
}

berais, de inspiração lockeana e rousseuniana. 0 contratualismo permeia a filosofia dos direitos humanos nos primórdios das constituições nacionais, o que faz com que sua gênese se ligue à conformação do próprio Estado de Direito. Nesse contexto, portanto, não se concebe Estado de Direitos sem direitos humanos, nem direitos humanos sem Estado de Direito. Essa vinculação leva Habermas a refletir sobre 0 caráter duplo desses direitos: como normas constitucionais, que fazem com que gozem de positividade (validação positiva), e também como direitos subjetivos reconhecidos aos indivíduos enquanto pessoa, 0 que lhes conferem uma validação sobrepositiva (HABERMAS, 2002, p. 213).

A dupla face dos direitos humanos leva a discussões acerca de eventual caráter pré-jurídico ou de direito natural ou então como produto de uma moral já vigente na sociedade. 0 que o legislador faria, de acordo com esses posicionamentos, é trazer para 0 direito positivo normas já existentes, sejam de caráter moral, sejam referentes ao direito natural ${ }^{9}$. Esses direitos, nessa concepção, são concebidos como direitos de todos os seres humanos por essa simples condição, não requerendo positivação nem contextualizações em ordens políticas. Habermas, no entanto, não adere a esses entendimentos, não concebendo direitos humanos pré-jurídicos ou fora de um ordenamento positivado e, ainda, democrático.

Nesse ponto, ele toca a questão da forma a seguir:

0 conceito de direitos humanos é de origem moral, mas também uma manifestação específica do conceito moderno de direitos subjetivos, ou seja, uma manifestação da conceitualidade jurídica. Os direitos humanos são já a partir de sua origem de natureza jurídica. 0 que Ihes confere a aparência de direito morais não é seu conteúdo, nem menos ainda sua estrutura, mas um sentido validativo que aponta para além das ordens jurídicas características dos Estados nacionais (2002, p. 214, grifo nosso).

9 Esclarece Habermas que essas formulações sugerem que o legislador constitucional traduz para a linguagem do direito positivo normas morais já existentes (HABERMAS, 2002, p. 213). 
Como integrantes, e ao mesmo tempo estruturadores das ordens jurídicas democráticas, os direito humanos gozam de validade em duplo sentido: não são apenas positivados e, por isso, dotados de coercibilidade, mas também dependem de uma legitimação racional. Como direitos constitucionais desfrutam de precedência sobre outros direitos plasmados em normas infraconstitucionais, sendo desfrutáveis pelos indivíduos em uma ordem democrática enquanto "seres humanos" e não dependentes de um status jurídico. Esse é o posicionamento de Habermas que revela que os direitos humanos, para serem usufruídos por um indivíduo, independem de sua condição legal ou status dentro de uma ordem jurídica, bastando que seja 'cidadão do mundo', pessoa, ou seja, não necessita da qualificação jurídica de cidadão dentro de um determinado Estado.

Assim, a face jurídica dos direitos humanos liga-se à sua positivação e ao fato de que somente podem ser cumpridos dentro de uma ordem jurídica nacional. Todavia, dirige-se a toda e qualquer pessoa albergada em um Estado, independentemente de gozar do status de cidadão daquela comunidade. "É essa validação universal, voltada a seres humanos enquanto tais, que os direitos fundamentais têm em comum com as normas morais" (HABERMAS, 2002, $p$. 215). Essa é a face que se volta para a moral.

Habermas busca essa validação universal sem recorrer à metafísica ou ao direito natural. A tentação de buscar uma validação pré-jurídica é grande, mas ele luta contra ela, partindo para uma fundamentação ao mesmo tempo universalista, que recorre à moral racional, e procedimental, que constrói a legitimação democrática, e, portanto racional e pósmetafísica $^{10}$. A universalidade, para o filósofo alemão, decorre exclusivamente do fato de serem fundamentados sob um ponto de vista moral. Habermas defende

\footnotetext{
10 Como exemplo, muitos autores distinguem direitos humanos de direitos fundamentais, afirmando que aqueles são direitos relativos aos seres humanos enquanto tais, e que, portanto, independem de positivação, possuindo força cogente por sua própria natureza. Já os direitos fundamentais são aqueles que constam das cartas constitucionais e cuja coercibilidade advém da positividade. Habermas é contrário ao posicionamento de que os direitos humanos independem da declaração em constituições, leis e tratados internacionais, defendendo que não há direitos humanos pré-jurídicos.
}

essa face moral dos direitos humanos sem enfraquecer seu caráter jurídico e aloca o conteúdo moral no conceito de dignidade humana.

é certo que as outras normas jurí-
dicas também são fundamentadas
com o auxílio de argumentos mo-
rais, mas em geral a fundamenta-
ção se dá igualmente com pontos
de vista ético-políticos e prag-
máticos que se referem à forma
de vida concreta de uma comu-
nidade jurídica histórica, ou então
ao estabelecimento concreto de
objetivos ligados a determinadas
políticas. (2002, p. 215).

Já os direitos fundamentais tratam de matérias de tal generalidade que são fundamentáveis moralmente (2002, p. 215). Por estarem relacionados à proteção à dignidade humana, cujo conceito faz a ponte entre 0 direito e a moral, não há como afastar sua pretensão de universalidade. Nada mais universal do que a dignidade humana. Regras positivadas para a proteção da dignidade são de interesse de todas as pessoas "na qualidade de pessoas em geral, ou ainda, por que elas são igualmente boas para todo mundo" (2002, p. 215).

Essa fundamentação, porém, não retira a necessidade de positivação, que é a chancela da garantia e efetividade. Em que pese a fundamentação moral, em nada ela prejudica a face jurídica desses direitos, não os transformando em normas morais. Eles são normas jurídicas de direito positivo, não obstante a natureza das razões que fundamentam sua pretensão de legitimidade. Se conceitos morais permeiam intrinsecamente os direitos humanos, não há como deixar de reconhecer a carga axiológica, que remete à pretensão à universalização.

\section{HABERMAS E 0 PROJETO DE DIREITO COSMO- POLITA}

"A imposição global de direitos humanos e democracia, que tem por tarefa fomentar a paz mundial, teria 0 efeito desintencional de extrapolar os limites da guerra 'comedida' e feita segundo 0 direito 
internacional" (HABERMAS, 2002, p. 222). Schmitt defendia uma filosofia belicista da vida, defendendo a paz jurídica estatal interior e um belicismo nos assuntos exteriores. A partir dessa visão, Habermas extrai 0 entendimento de que Schmitt considerava que era 0 universalismo da moral da humanidade, tal como conceituada por Kant, que estava por trás da "guerra contra a guerra", que assumia um "status endêmico de uma guerra civil paramilitar e descomedida" (HABERMAS, 2002, p. 222). Ainda, acentuou a incongruência dessas posturas anti-humanistas, como a inevitável distinção política entre amigo e inimigo, da qual a moral da humanidade abstrai erroneamente, segundo Schmitt; à infectação do direito internacional pela moral em nome de uma 'humanidade', à assimetria entre uma condição jurídica pacifista nos assuntos interiores e um belicismo nos assuntos exteriores, dentre outras.

Mas Habermas também leva em conta 0 contexto histórico no qual Schmitt desenvolveu suas teorias, partindo de sua aversão ao liberalismo e à democracia, nos termos colocados por Marcelo Cattoni, não obstante critique severamente seu anti-humanismo". Habermas toca no "sofrimento das vítimas marginalizadas dessa mesma civilização" (HABERMAS, 2002, p. 223), como o lado inverso dos vencedores, e rechaça a naturalização da guerra, como realidade pertencente à ordem natural, e a inevitável distinção entre amigos e inimigos, concernente ao que é político, promovidos por Schmitt. Ele reflete que "são as falsas abstrações da moral da humanidade que nos fazem mergulhar em auto-ilusão e nos desviam para uma auto-exigência demasiada e hipocrítica" (HABERMAS, 2002, p. 222-223).

A leitura habermasiana, a partir do sofrimento, exige uma atenção igualitária e de compaixão universal, que 0 universalismo moral trata de validar (HABERMAS, 2002, p. 223). Na busca por essa universalização, a preocupação com 0 sofrimento dos inocentes leva ao reconhecimento da dignidade como

11 Habermas reflete que, o que o anti-humanismo de Schmitt "pretende validar (em conjunto com o Hegel de Mussolini e de Lênin) não é 0 gado de abate, mas o combate - a mesa de abate dos povos, segundo Hegel, a 'honra da guerra'[...]” (HABERAMS, 2002, p. 223). ponte entre os direitos humanos e moral, sem que a imposição dos direitos humanos signifique uma moralização.

0 verdadeiro cerne da questão
consiste em que uma moralização
imediata do direito e da política
realmente faz romper as zonas
de defesa que, por razões boas
e mesmo morais, pretendemos
ver garantidas para as pessoas
do direito. É errônea, no entanto,
a suposição de que só poderia
evitar essa moralização caso se
mantivesse a política internacio-
nal isenta ou purificada do direito,
ou o direito isento e purificado da
moral (HABERMAS, 2002, p. 224).

Sob as premissas do Estado de Direito e da democracia, as duas coisas são falsas: a ideia do Estado de direito exige que, por meio do direito legítimo, a substância coercitiva do Estado seja canalizada tanto para fora quanto para dentro; e a legitimação democrática do direito deve garantir que 0 direito esteja em sintonia com as proposições morais fundamentais já reconhecidas. 0 direito cosmopolita é uma consequência da ideia do Estado de Direito. Só com ele é que se constrói uma simetria entre a ordenação jurídica do trânsito social e político, para além e para aquém das fronteiras do Estado (HABERMAS, 2002, p. 224). A política de direitos humanos de uma organização mundial pode, então, incidir em um fundamentalismo dos direitos humanos. Entretanto, isso só ocorre, quando essa política, "sob o manto de uma pseudolegitimação jurídica - confere legitimação moral a intervenções que não passem do mero combate de um partido por outro" (HABERMAS, 2002, p. 224-225).

Carl Schmitt, para Habermas, tenta sustentar a posição de que a imposição internacional de direitos humanos em um cenário dominado por forças militares resulta sempre e necessariamente em um fundamentalismo dos direitos humanos. Porém essa afirmação é falsa, porque subjaz a ela a falsa premissa de que os direitos humanos sejam de natureza moral, ou seja, de que a imposição dos direitos humanos significaria uma moralização. Isso não é verdade. A face 
problemática de uma ordenação moral das relações internacionais não consiste em que uma ação política deva ajustar-se a categorias jurídicas. Pois, diferentemente do que faz a moral, o código jurídico não exige de modo algum uma valoração moral imediata segundo critérios de 'bom' ou 'mau' (HABERMAS, 2002, p. 226). Excluir uma interpretação política, no sentido de Schmitt, do comportamento que contraria os direitos humanos não pode implicar que uma interpretação imediatamente moral venha a ocupar seu lugar (Klaus Günther) (HABERMAS, 2002, p, 26). Direitos humanos não podem ser confundidos com direitos morais. Todavia, a diferença entre direito e moral não significa que 0 direito positivo não tenha um teor moral.

No procedimento democrático legislativo, os argumentos morais desempenham papel na fundamentação do estabelecimento de normas, repercutindo, claro, no próprio direito. "Como já dissera Kant, 0 direito e a moral distinguem-se por qualidades formais de legalidade" (2002, p. 226). Mas nem todo comportamento passível de julgamento moral é ou deveria ser positivado, eles ficam eximidos da juridificação por pertencerem, muitas vezes, a um ethos social, a sentimentos morais, motivos, inclinações, tradições que dispensam a invasão, ou no dizer de Habermas, a colonização do mundo da vida pelo direito. Enquanto a pessoa moral fica exposta ao julgamento da consciência, a pessoa do direito permanece "envolvida no manto dos direitos à liberdade - moralmente bem fundamentos" (HABERMAS, 2002, p. 227).

A resposta ao perigo de uma moralização da política expansionista e de poder, sem qualquer mediação, "não é isentar a política de uma dimensão moral, mas sim transformar a moral, por via democrática, em um sistema positivado de direitos, dotado de procedimentos jurídicos para sua aplicação e imposição". Assim sendo, não se pode "evitar o fundamentalismo dos direitos humanos por meio da renúncia a uma política de direitos humanos, mas apenas por meio da transformação cosmopolita da condição natural entre os Estados em uma condição jurídica entre eles". (HABERMAS, 2002, p. 227). Essa é a forma que Habermas encontra para abrandar o posicionamento kantiano quanto à paz perpétua, afastando a ilusória ideia de lei cosmopolita de Kant, principalmente porque ele não traça um caminho para alcançar esse tipo de lei, abrangente e universal e porque a fundamenta na frágil base de uma coesão moral, de uma ordem moral cosmopolita.

Em contrapartida, Habermas não subordina a lei à moral, resistindo à ideia de que uma ordem jurídica cosmopolita pode ser deduzida de uma ordem moral cosmopolita. Para Habermas, portanto, as leis globais legítimas devem ser democraticamente estabelecidas, por meio de uma ordem mundial administrada por um sistema democrático organizado, supranacional, estando no topo a Organização das Nações Unidas, cujas atribuições precípuas deveriam ser de proteger os direitos humanos e promover a paz mundial e com a criação de um órgão executivo internacional com poderes executórios legítimos, para fazer cumprir os direitos humanos em casos de violação. A força obrigatória do direito cosmopolita, estatuído a partir de uma ordem mundial constitucionalizada, não incidiria somente sobre indivíduos, cidadãos do mundo, mas também sobre governos.

A soberania dos Estados sofre, portanto, abrandamento em prol da efetividade e garantia dos direitos humanos. Enquanto isso, Habermas insiste que a política global de direitos humanos deve ser mediada por lei e adverte contra 0 que denomina de "fundamentalismo dos direitos humanos", ressaltando que a maneira de evitar o fundamentalismo dos direitos humanos não é "renunciar à política dos direitos humanos", mas lutar por uma política "cosmopolita de transformação do estado da natureza entre os estados em uma ordem jurídica" (HABERMAS, 2002, p. 201).

0 direito cosmopolita deve ser estabelecido por meio de um processo formal de democracia global - ou seja, a lei cosmopolita deve ser estabelecida formalmente por meio dos meios formais de discussão, votação, e assim por diante. 0 conceito de processo formal de democracia global deve ainda ser construído, de forma a permitir a participação equânime e com observância à paridade de todos os Estados e comunidades envolvidas. Ainda, a lei deve ser estabe- 
lecida de forma democrática, devendo ser cumpridas algumas condições: i) um congresso mundial legítimo que consiste em representantes legítimos de diferentes povos ou de todos os cidadãos no mundo; ii) discussões formais e democráticas, globalmente; iii) procedimento formal de votação democrática; iv) processo justo, formal e democrático formal, previsto em lei; v) participações democráticas completas na escala global, seja pelos próprios cidadãos ou por seus representantes legítimos. Trata-se de uma democracia em escala global, para garantir a efetividade de uma política universal de direitos humanos e, assim, possibilitar a perseguição de uma ideia de paz mundial.

\section{CONSIDERAÇÕES FINAIS}

A construção dialógica do teor cognitivo de uma moral universal, do direito e de sua legitimidade devem considerar as duas dimensões de reconhecimento: uma relativa ao indivíduo perante a sociedade, e outra coletiva, que é o reconhecimento da identidade do grupo frente a outros. E é dessas dimensões que advém a necessidade de compreender a equiprimordialidade entre autonomia privada e autonomia pública, como necessárias à institucionalização do reconhecimento das minorias identitárias excluídas.

Ora, em sociedades acentuadamente pluralistas, as políticas de reconhecimento e de promoção das identidades excluídas devem passar pelo médium do direito, mormente pelo reconhecimento de direitos fundamentais a todos aqueles que se refugiam em um novo Estado. Cuida-se de uma política de universalização dos direitos humanos que devem ser garantidos a todo ser humano, como cidadão, seja de uma comunidade jurídica em particular, seja do mundo (HABERMAS, 2002; 2012).

Trata-se não de rechaçar o nacional, mas de incluir o 'outro'. Essa universalização, para Habermas, decorre das exigências legítimas de uma justiça que não pode fechar os olhos para aqueles que recorrem a outros Estados democráticos com vistas a gozarem efetivamente de direitos que deveriam ser assegurados a todos indivíduos, mundialmente. E esse reconhecimento deve incluir tanto a garantia de uma possibilidade de vida material para os não nacionais, quanto o reconhecimento do igual valor de identidades dos excluídos no status da cultura comum. É nessa esteira que Habermas constrói sua teoria da inclusão do outro na obra em comento.

Ele foca mais na inclusão e reconhecimento dos excluídos nas nações que se abrem para dentro e se fecham para fora, a partir da atribuição de mesmos direitos e garantias por meio da prática do discurso. A abordagem que aqui interessa é a discursiva. Habermas entende que a estabilização de uma sociedade pluralista somente por meio de uma força "vinculativa da comunitarização republicana é insuficiente para isso" (HABERMAS, 2002, p. 150). Ele, portanto, não cuida na integração econômica dessas minorias, o que não retira a força legitimadora de sua filosofia para a fundamentação das políticas de inclusão, acreditando que a lealdade do cidadão "precisa de uma ancoragem na consciência da solidariedade do povo, marcada por uma primordialidade natural e pelo destino histórico". A inclusão de todos no status de cidadãos abre para o Estado uma fonte secular de legitimação e também "produz um novo patamar para uma integração social abstrata, juridicamente mediada" (HABERMAS, 2002, p. 151).

Se a solidariedade é indispensável, em um primeiro momento, à convivência de pessoas estranhas umas para as outras, a transformação universalista das lealdades tradicionais para os iguais, familiares, congêneres, é um processo difícil e, sobretudo, longo, sendo a noção de solidariedade cara ao arranjo coeso e estável entre nacionais e diferentes. Nesse contexto, Habermas defende a necessidade de reconhecimento de direitos fundamentais às minorias dentro das ordens jurídicas parciais bem como a garantia em nível mundial dos direitos humanos, a partir da universalização possível mediante um processo democrático formal global, com a participação dos concernidos no discurso de elaboração das normas cosmopolitas. Mas, se há hodiernamente diversos Estados não democráticos, como ratificar uma democracia mundial 
com participação de todas as comunidades do globo?

0 projeto cosmopolita como Habermas concebe é digno. Ele centra a importância na construção do consenso, que para ele possui como condição 0 comportamento ético dos interlocutores e a força ilocucionária da linguagem, possibilitada pelo agir $\mathrm{Co}^{-}$ municativo. Ou seja, os interlocutores não poderão se comportar de forma estratégica, como usualmente 0 fazem, mormente na política, mas devem buscar 0 entendimento mútuo por meio do agir comunicativo, respeitando determinadas regras, ou pretensões de validade do discurso, sendo elas a veracidade, a sinceridade, a normatividade e a universalidade.

\section{REFERÊNCIAS}

COELHO, A. Distinguindo cinco posições metaéticas. Disponivel em: <http://aquitemfilosofiasim. blogspot.com.br/2013/12/distinguindo-cinco-posicoes-metaeticas.html>. Acesso em: 22 out. 2017.

DUTRA, D.J.V. Direitos, deveres não: 0 teor cognitivo da moral moderna. Disponível em: <http://revistaseletronicas.pucrs.br/ojs/index.php/veritas/article/ view/9845/7318>. Acesso em: 25 out. 2017.

FLYNN, J. Habermas on Human Rights: Law Morality Intercultural Dialogue. 2011. Disponível em: <https:// www.academia.edu/3245623/Habermas_on_Human_Rights_Law_Morality_Intercultural_Dialogue>. Acesso em: 21 out. 2017.

HABERMAS, J. Lutas pelo reconhecimento no Estado democrático constitucional. In: TAYLOR, Charles. Multiculturalismo: examinando a política de reconhecimento. Lisboa: Instituto Piaget, 1994. p. 125-164.

TAYLOR, C. A inclusão do outro: estudos de teoria política. São Paulo: Loyola, 2002.

TAYLOR, C. Consciência moral e agir comunicativo. Tradução de Guido A. de Almeida. Rio de Janeiro: Tempo Brasileiro, 2003a.
TAYLOR, C. Direito e Democracia: entre facticidade e validade. 2. ed. Tradução de Flávio Beno Siebeneichler. Rio de Janeiro: Tempo Brasileiro, 2003b. Vol. I.

NEVES, M. L. Habermas e o Estado de Direito. Lua Nova, n. 37-96, p. 93-106, 1996. Disponível em: <http://www.scielo.br/pdf//n/n37/a06n37.pdf>. Acesso em 06 out. 2017.

OLIVEIRA, M.A.C.; ALVES, A.D. Carl Schmitt: um teórico da exceção sob um estado de exceção. Disponível em: $<$ http://www.ufjf.br/siddharta_legale/files/2014/07/ Carl-Schmitt-0-teorico-da-excecao-sob-estadode-exccecao.pdf>. Acesso em: 21 out. 2017.

RUTA, C. Defensor da democracia, filósofo Jürgen Habermas completa 85 anos. Deutsche Welle, $18 \mathrm{de}$ junho de 2014. Disponível em:<http://www.dw.com/ pt-br/defensor-da-democracia-fil\%C3\%B3sofo-j\%C3\%BCrgen-habermas-completa-85-anos/a-17717753>. Acesso em: 25/05/2017.

REGH, W. Insight \& Solidarity: The Discourse Ethics of Jürgen Habermas. Los Angeles: University of California Press, 1997.

Recebido em: 29/04/18 Aceito em: 29/05/2018 